\title{
Da margem no centro: deslocamentos do sujeito no feminismo *
}

\section{The margin in the center: subject's displacements in feminism}

Dra. Fernanda Alt

fernandaalt@gmail.com

UERJ | Paris 1 Pantheón-Sorbonne

Pós-Doutoranda [UFSCar] **

$\int$ Este artigo aborda a questão do sujeito no feminismo por uma perspectiva fenomenológica do espaço no intuito de compreender as divisões sociais como lugares a serem habitados por determinados sujeitos. A partir de uma posição de Gayatri Spivak sobre o movimento centralizador, pretende-se entender de que modo aquilo que é produzido como margem, ao deslocar-se para que é estabelecido como central, quebra a pretensa neutralidade e universalidade deste centro, desestabilizando, ao mesmo tempo, a própria divisão. Assim, o "autocentramento" do sujeito universal é aqui analisado como um lugar produzido e sustentado pelo movimento centralizador - com destaque na sua legitimação pela linguagem -, colocando como "outro", "diferente" ou mesmo "não existente" tudo o que é por ele conduzido à margem. Desta forma, as experiências de deslocamentos aparecem como possibilidade de, mais do que inverter o dualismo margem/centro, subvertêlo de modo a desnaturalizá-lo e assim combater tais tipos de exclusão abrindo espaços para outras formas de habitar o mundo.

PALAVRAS-CHAVE $\begin{aligned} & \text { Sujeito. Feminismo. Fenomenologia do espaço. } \\ & \text { Margem e centro. Linguagem }\end{aligned}$ 
This article discusses the issue of the subject in feminism from a phenomenological perspective of space in order to understand social divisions as places to be inhabited by certain subjects. From Gayatri Spivak's position about the centralizing movement, it is intended to understand how that which is produced as a margin, by moving to what is established as central, breaks the supposed neutrality and universality of this center, destabilizing at the same time the division itself. Thus, the "self-centring" of the universal subject is here analyzed as a place produced and sustained by the centralizing movement - with emphasis on its legitimization in language - as that which produces exclusion by placing as "other", "different" or even "non-existent" everything that is led by it to the margin. In this way, the experiences of displacement appear as a possibility of, rather than inverting the dualism margin/center, subverting it in order to denaturalize it and thus combat such types of exclusion by opening spaces for other ways of inhabiting the world.

\section{KEYWORDS Subject. Feminism. Phenomenology of space. \\ Margin and center. Language}


A única maneira pela qual posso sugerir como o centro em si é marginal é não ficando de fora na margem apontando o meu dedo acusador para o centro. Ao invés disso, eu posso fazê-lo implicando-me no centro e sentindo que política o torna marginal.

Gayatri Spivak

Estar na margem é fazer parte do todo, mas fora do corpo principal.

bell hooks

A "questão do sujeito" é um dos grandes temas da filosofia contemporânea. Ao seu redor, orbitam posições que anunciam sua morte e outras sua restauração. De todo modo, prevalece a crítica ao sujeito racional e consciente em prol de algo mais obscuro, algo que é como uma produção ou uma criação (BADIOU, 2012), o que faz do século XX, segundo Badiou, "uma imensa discussão sobre Descartes", inventor da categoria de sujeito (p. 12). No campo feminista, este debate parece ir além, ao tornar evidente as consequências políticas de tais posições no que diz respeito ao "sujeito" do feminismo. As problemáticas da substancialidade, da identidade e da universalidade neste contexto explicitam o quanto tais elaborações ontológicas, dadas na maioria das vezes como "neutras", são as bases produtoras e sustentadoras de exclusão. Deste modo, as lutas dos chamados sujeitos minoritários em geral, e neste caso dos sujeitos do feminismo em particular, vêm deslocar a centralidade até mesmo do mais "desconstruído" sujeito universal. Sobre tais questões, o capítulo que abre Problemas de gênero de Judith Butler é de fato um marco ao colocar muitos "problemas", na sua acepção do termo, assinalando que a luta feminista busca emancipação por via da representatividade de sujeitos que são produzidos pelo próprio poder de exclusão, apontando ao mesmo tempo para a linhas invisíveis de tal produção. Diz Butler:

A questão do "sujeito" é uma questão crucial para a política, e para a política feminista em particular [ ] $a$ construção política do sujeito procede por certos objetivos de legitimação e de exclusão, e essas operações políticas são efetivamente ocultas e naturalizadas por uma análise política que toma as estruturas jurídicas como seu fundamento (BUTLER, 1990, p.2, grifo meu). 
Para Butler, as próprias concepções de sujeito são efeitos de poder, como já mostrava Foucault, dado que são produtos de "ficções fundacionistas" que tendem a pressupor uma entidade anterior ao campo cultural. Tendo em vista esse movimento de produção e exclusão próprio à construção de posições de sujeitos, me interessa neste momento pensar a questão por outro caminho ${ }^{1}$. No campo da fenomenologia, a crítica ao sujeito cartesiano se deu, com relação a esta atmosfera do debate filosófico contemporâneo, também ora pela tentativa de superá-lo, ora de restaurá-lo. De modo geral, pode-se dizer que os problemas de dualismo e de substancialismo na filosofia cartesiana se sobressaem como problemas maiores. Neste contexto, uma forma inaugural de se pensar a temporalidade permitiu que os fenomenólogos encontrassem os meios para outra concepção de sujeito que, por ser temporal, não poderia admitir as características de identidade a si e substancialidade.

Já na perspectiva atual da "fenomenologia do pertencimento" de Renaud Barbaras, vislumbra-se outra alternativa ao se considerar um sujeito não substancial por uma perspectiva diversa, desta vez pelo privilégio do espaço (sendo o próprio tempo uma de suas dimensões). Em poucas palavras, isto significa, naquilo que interessa para o que está sendo tratado aqui, que a questão do "lugar" é constitutiva dos modos de ser dos sujeitos ou que "nossa identidade de sujeitos, longe de se apoiar em alguma entidade espiritual ou subjectiva, confunde-se com o pertencimento a determinado mundo, ou seja, com a abertura de um determinado lugar ${ }^{2}$ " (BARBARAS, 2019, p. 36). Esta ideia de que o sentido dos modos de ser dos sujeitos encontra-se sobretudo ligado à questão "onde?", ao invés da questão "quem?" (priorizada por Heidegger, por exemplo), me parece inspiradora no intuito de pensar a produção de "lugares" a serem habitados por diferentes caracterizações de sujeitos numa arrumação social.

Neste artigo em particular, gostaria de me concentrar nestes arranjos que envolvem uma força de centralização ao mesmo tempo produtora tanto de marginalizações quanto da própria divisão centro/margem. Desta forma, creio ser possível vislumbrar uma espécie de arrumação de um campo fenomenal polí-

1 Dado que os problemas trazidos por Butler mereceriam um artigo à parte. Sobre Butler e a questão do sujeito, ver, por exemplo: RODRIGUES, C. ; LOBATO, A.E. "Os feminismos e seus sujeitos" Princípios: Revista de Filosofia, Natal, v. 27, n. 52, jan.-abr. 2020 ; CYFER, I. "Afinal, o que é uma mulher? Simone de Beauvoir e 'a questão do sujeito' na teoria crítica feminista. Lua Nova, São Paulo, 94: 41-77, 2015.

2 Barbaras (2019) distingue na verdade 3 níveis de pertencimento: o local (site) que denota um sentido topológico; o solo ( $\mathrm{sol}$ ) que diz respeito ao pertencimento a um solo ontológico comum; e o lugar (lieu) que concerne o movimento ativo de fenomenalização de um sujeito. Ver: Cap. 2 "Les trois sens de l'appartenance" de L'appartenance. Vers une cosmologie phénoménologique. 
tico, no qual certos lugares são revestidos de estatutos ontológicos legítimos - colocados como "central", "modelo" e "neutro", enquanto outros são marginalizados por diferentes processos: seja por invisibilização (como um lugar do não-lugar, próprio a sujeitos invisíveis, não existentes), seja como o "outro" (menor, inferior), seja até mesmo e simplesmente como "diferente" (o que só pode aparecer como tal com relação a um centro de gravidade que legitima certa zona de identificação como modelo).

Inspirada pelo gesto desconstrutor de Gayatri Spivak, penso que tal arrumação que configura os estatutos ontológicos dos sujeitos nessa dinâmica espacial pode ser revelada pelo trânsito dos habitantes colocados à margem pelo território considerado central (no sentido também de "principal"). $O$ foco aqui é neste trânsito, nesta presença do que é da margem no centro, a fim de evidenciar a própria produção do dualismo excludente e de desnaturalizar os modelos de sujeito autocentrados.

\section{Inverter e deslocar: travessias}

Na conferência intitulada "Explanation and Culture: marginalia" Spivak (1996) mostra, partindo da própria situação em que se encontra, que os discursos explicativos oficiais são assegurados sobretudo por uma estrutura de marginalização e centralização. Sua intervenção revela na prática, ao analisar aspectos de outras falas do evento para o qual fora convidada, como se faz um gesto desconstrutor de descentralização que implica simultaneamente desmarginalizar aquilo que é expulso necessariamente por uma força central.

Inspirada pelo trabalho de Derrida, Spivak enfatiza que tal gesto desconstrutivo não é apenas a inversão de uma oposição binária, mas sim uma inversão-deslocamento. Isto tendo em vista que o pensamento centralizador é tipicamente produtor de binarismos, na medida em que o empenho explicativo, em sua pretensão de conquistar conceitualmente um determinado campo, o divide (p. 42). No que tange à questão do sujeito, esse quadro revela uma posição ontológica implícita. Na linguagem fenomenológica, tal posição reenvia a uma concepção quanto ao a priori correlacional: de que modo se concebe sujeito e objeto? Qual seria este sujeito capaz apreender completamente ou dominar aquilo de que se trata? Para Spivak, 
a vontade de explicar é o desejo de ter um eu e um mundo. Em outras palavras, no nível geral, a possibilidade de explicação traz o pressuposto de um universo explicável (mesmo que não completamente) e um sujeito explicativo (mesmo que imperfeito) [...] Em um nível mais específico, toda explicação deve segurar e assegurar um certo tipo de ser-no-mundo, que pode também ser chamado de nossa política (SPIVAK, 1996, p. 33)

Spivak mostra que Derrida desconstrói o papel da "expressão" como linguagem adequada da teoria em $A$ voz e o fenômeno, seu livro sobre a questão do signo em Husserl. É fundamental para ela que o livro conclua evidenciando a vontade que perdura ao longo da história da metafísica de ouvir somente um falar sozinho (hear-onself-speak). Não se trata, porém, da possibilidade de colocar-se fora de qualquer explicação, mas sim de saber que toda explicação afirma sua centralidade a partir de uma margem excluída que indica ao mesmo tempo aquilo que pode ser expresso (SPIVAK, p. 34). É nessa margem excluída que ela inicialmente se situa, de onde realiza o gesto desconstrutor. Mas, ao assumir a margem e recusar uma relação de apropriação do centro, ela inverte e desloca. Enquanto feminista, "habitante das margens" cujo centro é masculinista, o gesto a ser feito não é o de "ganhar o centro" para as mulheres, mas, em primeiro lugar, o de apontar a "irredutibilidade das margens em todas as explicações" (SPIVAK, 1996, p. 33) e assim superar a própria divisão. Para isso, as habitantes das margens, ao invés de conquistar o centro pra si, transitam de modo a deslocar o próprio centro e expor o seu poder de dividir:

\footnotetext{
A única maneira pela qual posso sugerir como o centro em si é marginal é não ficando de fora na margem apontando o meu dedo acusador para o centro. Ao invés disso, eu posso fazê-lo implicando-me no centro e sentindo que política o torna marginal. (SPIVAK, 1996, p. 35)
}

É neste sentido que Spivak se coloca como um "transporte" (shuttle) entre o centro (dentro) e a margem (fora) [para] assim narrar um deslocamento" (ibid, grifo meu). Gloria Anzaldúa e Cherríe Moraga (1983) falam em construir pontes; no sentido de um movimento, pois a ponte em This Bridge called my back não aparece como a metáfora de uma estrutura rígida entre dois polos isolados. A ponte surge como possível construção de um acesso transformador e neces- 
sário a outro lugar; como materialização de "ritos de passagem" (BAMBARA, 1983, p.vii), como aquilo que se faz viajando, caminhando (ANZALDÚA, p. v). $\mathrm{O}$ deslocamento se dá assim entre polos de partida que não são tampouco fixos. Como diz Preciado a respeito de posições determinadas para os sujeitos: na verdade, "nós estamos sempre em uma encruzilhada" de modo que "o cruzamento é o único lugar que existe" (2019, p. 30). Um "lugar" que não é um lugar no sentido topológico, mas é atopos, a meu ver, modos existenciais de habitação, por entre os quais transitamos. Preciado chama de travessia os possíveis deslocamentos e inúmeras são as fronteiras que podem ser cruzadas no atravessar. No seu caso particular, a chamada "mudança de sexo" o fez um "viajante do gênero" (2019, p. 30), cuja ponte, como a de Anzaldúa, é o habitar a encruzilhada: "Eu sou uma ponte balançada pelo vento, uma encruzilhada habitada por redemoinhos", diz Anzaldúa (1983, p. 228). A travessia é então o momento de des-identificação, de descentramento da posição de sujeito que até então era ocupada. É "o lugar da incerteza, da não obviedade, da estranheza. Não é uma fraqueza, é uma potência" (PRECIADO, 2019, p. 37). Proponho que a travessia do deslocamento possa ser uma ferramenta para o objetivo de fazer aparecer as hierarquias até então invisíveis na produção dos sujeitos e, como tal, uma prática no campo feminista.

\section{Deslocamentos dos sujeitos pelo e no feminismo: os centros de gravidade}

Já é célebre o passo de Beauvoir ao apontar a exclusão da mulher nas teorias do sujeito. Ao fazê-lo, a autora provoca uma quebra na "seriedade"3 de cada teoria que inquestionavelmente parte de um sujeito universal, neste caso, no que tange à divisão assimétrica entre homens e mulheres. Neste sentido, como afirma Elsa Dorlin, “[os] saberes feministas, [...] não só produzem novos conhecimentos sobre as mulheres como também desqualificam o 'verdadeiro conhecimento', perturbam a economia do próprio conhecimento e a distinção entre sujeito e objeto do conhecimento" (2008, p. 13). Beauvoir destaca que a "humanidade" é "macho": "A relação entre os dois sexos não é a dos dois pólos

3 Numa referência ao "espírito de seriedade" tal como pensado por Sartre ao longo de sua obra literária e filosófica. Trata-se de um conceito que mostra que as naturalizações dos lugares legítimos mascaram a condição da existência que é a de se "estar em questão", a saber, como um tipo de "má-fé". Para o espírito de seriedade, essas posições não aparecem como lugares acordados intersubjetivamente, mas sim como hierarquias e valores naturais, não questionáveis, de onde certos indivíduos aparecem como possuindo o direito "ontológico" de existir e outros não. 
elétricos, dos dois pólos: o homem representa ao mesmo tempo o positivo e o neutro, a ponto de dizermos em francês "os homens" para designar os seres humanos" (2014, p. 16, grifo meu) de maneira que "tal como para os antigos havia uma vertical absoluta com relação à qual o oblíquo era definido, há um tipo humano que é o tipo masculino" (p.17); “[a mulher] é o inessencial diante do essencial. Ele é o Sujeito, ele é o Absoluto: ela é o Outro" (ibid.). Consequentemente, a denominação "mulheres" é sempre para-outro, as mulheres não se colocam neste lugar - Sujeito - não dizem "nós" (p. 21).

Se nos concentrarmos no movimento de centralização e marginalização, vemos claramente a divisão dos lugares a serem ocupados pelos diferentes gêneros e para onde tende o centro de gravidade. É como se numa determinada cidade o "centro" fosse habitado pela verdade, pela seriedade e pelo modelo, enquanto o periférico pela meia-verdade, pela simulação e pelos simulacros. Neste sentido, e de forma geral, o lugar "mulher" é periférico. Entretanto, o centro não se coloca como centro, mas como "positivo" e "neutro", como indica Beauvoir. É o lugar de onde tudo provém, ao redor do qual tudo circula e outros lugares orbitam ${ }^{4}$. Nesta centralização, que institui "o" lugar fundante, não trazendo quebra na divisão de forças, o dado sujeito "masculino", com efeito, não tem gênero, ele é apenas o "sujeito". Em "Le point de vue: universal ou particulier", Monique Wittig reforça esta constatação ao dizer que "o masculino não é o masculino, mas o geral. O que faz com que haja o geral e o feminino, a marca do feminino" (2018, p. 114). Com base nesse sujeito não marcado, equivalente ao geral, se edifica um pensamento, cria-se conceitos igualmente universalizantes. Consequentemente, a marginalização cria o outro como diferente, ou seja, como não condizente com a "normalidade" universal, que é onde se instala o centro de gravidade. Através dessas linhas de força os lugares são definidos de forma assimétrica, hierárquica e binária: a "mulher" com relação ao "homem", o "negro" com relação ao "branco", o "homossexual" com relação ao "heterossexual", o "trans" com relação ao "cis", o "oriental" com relação ao "ocidental", entre outras divisões próprias ao patriarcado colonial. No caso da pressuposição da diferença sexual, ou seja, da divisão entre homens e mulheres, Wittig denomina de pensée straight este pensamento que universaliza tal diferença num regime político de heterossexualidade compulsória. Isto é, não se trata de pensar somente a heterossexualidade como uma prática sexual considerada "normal", com relação a qual outras práticas são patologizadas, mas os lugares políticos instituídos pela cultura da diferença sexual. Nas palavras de Wittig:

4 No aspecto geográfico da questão, pode-se pensar no caso da França, onde todo o território do país que não corresponda a Paris é chamado de "província" (province). Ou seja, o que há é Paris e a province (Não confundir com a região de Provence). 
A consequência de,sta tendência para a universalidade é que o pensamento heterossexual não pode conceber uma cultura, uma sociedade em que a heterossexualidade não ordenaria não somente todas as relações humanas, mas a sua produção de conceitos ao mesmo tempo que todos os processos que escapam à consciência. (WITTIG, 2018, p. 73)

Aqui vemos como um modelo explicativo das identidades e das sexualidades equivale a um sistema de pensamento universalizante centralizador e binário (termos que se implicam reciprocamente, como vimos). A heterossexualidade como regime político - e não como mera prática sexual - instaura a diferença sexual como "natural" a partir da qual o masculino é o geral e o feminino é o gênero marcado ${ }^{5}$. É neste sentido que Wittig acredita que a denominação "mulher" só faz sentido em oposição ao termo "homem" no interior do regime heterossexual. Tais denominações são, na verdade, categorias políticas, pois a naturalização da diferença sexual mascara um conflito de classes, onde uma classe - "homens" - explora a outra, "mulheres", violência justificada pelo pensamento heterossexual. Assim resume Wittig:

O conceito de "diferença de sexos", por exemplo, constitui ontologicamente as mulheres em outros diferentes. Os homens, eles não são diferentes (tampouco os Brancos aliás, nem os senhores, mas os Negros são e os escravos também). Ora, para nós, não há nada como ser-mulher ou ser-homem, "homem" e "mulher" são conceitos de oposição, conceitos políticos. E dialeticamente a cópula que os une é ao mesmo tempo aquela que os suprime, é a luta de classes entre homens e mulheres que irá abolir os homens e as mulheres. E a função da diferença é mascarar conflitos de interesse em todos os níveis, incluindo o ideológico. (WITTIG, 2018, p. 73)

No materialismo feminista radical de Wittig, portanto, a luta não é somente pela transformação econômica de uma tal exploração mas, principalmente, pela destruição do pensamento dominante com seu modo de constituir os sujei-

5 Para Luce Irigaray, dá-se o inverso, isto é, somente o gênero masculino é marcado, sendo o feminino o "irrepresentável" na linguagem falocêntrica, como observa Butler (1990). 
tos: dividindo-os entre neutros e marcados. Isto implica em transformações em outras ordens igualmente materais como a linguagem. No romance Les Guérillères, Wittig desloca o sujeito masculino-unitário-universal: o personagem principal é "elas", de modo que x leitxr possa se encontrar num "espaço para além das categorias de sexo" (2018, p. 151). Experiência de descentramento que se dá neste habitar um espaço na própria duração do livro, isto é, mais do que um movimento de condução por uma temporalidade linear, este habitar revela a experiência de dispersão por um texto onde "o centro está em toda parte" (p. 152). E elas dizem o seguinte:

Elas dizem que lhes foi dado como equivalentes a terra o mar as lágrimas o que é húmido o que é preto o que não queima o que é negativo aquelas que se rendem sem combater. Elas dizem que esta é uma concepção que provém de um raciocínio mecanicista. Ele faz uso de uma série de termos que são sistematicamente relacionados com termos opostos. Seus padrões são tão grosseiros que desta memória elas riem com violência. Elas dizem que elas podem também ser relacionadas ao céu aos astros em seus movimentos de conjunto e em seus arranjos as galáxias os planetas as estrelas os sóis o que queima aquelas que combatem com violência aquelas que não se rendem. (WITTIG, 2019, p. 107-108)

Elas mostram tanto as falsas equivalências, quanto a restrição pela qual estas correlações se dão - mecanicista -, dando a sentir, também pelo riso, uma força de expansão que relaciona outros elementos impensados. Por elas, Wittig inverte e desloca. Não se trata de uma simples inversão do masculino pelo feminino, do singular pelo plural. Já é conhecida a crítica de Wittig à ideia de "escrita feminina"(Cf. p.113), que reforça justamente o "mito do feminino", armadilha exposta longamente por Beauvoir a todo momento em $O$ segundo sexo. Em outras palavras, não se trata de substituir a categoria política "homem" pela categoria política "mulher", de modo a permanecer no mesmo regime heterobinário. No entanto, se "mulheres" é entendido não como um grupo natural mas como classe - como produto de uma relação social -, compreendemos de que modo a inversão é, na realidade, uma inversão-deslocamento: "elas" é a classe "mulheres" (les femmes) que luta para destruir o sistema de pensamento que nutre o mito "a-mulher" (la-femme), seja como produto de uma determinação 
biológica, seja como naturalização inclusive do que é socialmente estabelecido como "feminino". A primeira tarefa, segundo Wittig é então a de dissociar as "mulheres" enquanto classe de "a-mulher", o mito : "porque, para nós, a-mulher não existe, ela é somente uma formação imaginária, enquanto que "as mulheres" são o produto de uma relação social. Devemos além disso destruir o mito dentro e fora de nós" (2018, p. 60, grifo meu).

Este risco aponta para outra esfera de centralização e marginalização, desta vez dentro do próprio campo feminista. Já faz algumas décadas que a questão da "essencialização" ou da identidade "mulher" é debatida no feminismo como produtora de exclusão, ao igualar "mulheres" que vivem situações de exploração e opressão fortemente desiguais (o que torna problemático reuni-las enquanto "classe"). Kimberlé Crenshaw se tornou referência ao apresentar os pontos de "interseção" como ponto de sobreposição de diferentes tipos de opressão que se retroalimentam justamente nessa junção. Aqui, este espaço onde os eixos se encontram não adquire visibilidade justamente por ser um "lugar dificilmente acessível à linguagem" (CRENSHAW, 2005, p. 53). Em seu artigo "Cartographies des marges : intersectionnalité, politique de l'identité et violences contre les femmes de couleur", Crenshaw mostra de que modo os sistemas patriarcal e racista se influenciam mutuamente e sobretudo como o processo de marginalização das pessoas de cor se dá pelos discursos e práticas das feministas brancas. Assim, o conceito de intersecionalidade permite descrever esta espécie de lugar designado à mulheres de cor, "colocadas simultaneamente em sistemas de subordinação intersectados e nas margens do movimento feminista e anti-racista" (p. 74) ${ }^{6}$.

Deste modo, a marginalização é efeito da combinação das exclusões. bell hooks (1990) também aborda este tipo específico de lugar marginalizado em Ain't I a woman? ao relatar vários fatos históricos e passagens literárias que produziram o apagamento da mulher negra, inclusive no pioneirismo do movimento feminista. Ela retoma a história de Soujourner Truth, que percorreu o caminho da escravidão à liberdade, quando indagou: "Eu não sou uma mulher?". Diante de uma plateia branca na "Segunda convenção anual dos direitos

6 No entanto, para Crenshaw, o movimento importante não é somente o de realizar uma crítica antiessencialista, dado que esta pode resultar no que ela identifica como sendo um "construtivismo vulgar" - que reduz as categorias a puras construções sociais sem importância para lutas políticas da identidade - de modo que nem "negros" nem "mulheres" existam. A vulgarização do construtivismo, segundo ela, distorce o sentido das construções sociais trazendo prejuízos para a luta política : a seu ver, a identidade é lugar de resistência para diferentes grupos subordinados na medida em que nela pode-se afirmar aquilo que era então marginalizado. Afirmar a universalidade da "pessoa", por exemplo, ao invés de colocar-se politicamente em sua identidade, produz o enfraquecimento das estratégias de resistência. (2005, p.76-77) 
das mulheres "em Ohio em 1852, logo após a fala de um homem branco que se opunha à igualdade de direitos para as "mulheres", alegando serem estas muito fracas para o trabalho, Truth exclama:

[...] Olha pra mim! Olha para o meu braço! [ ] Eu podia trabalhar tanto quanto qualquer homem (quando podia) [ ] eu pari cinco crianças e vi quase todos vendidos à escravidão, e quando eu chorei com uma dor de mãe, só Jesus escutava, não sou uma mulher? (TRUTH apud hooks, 1990, p. 160).

Não era somente os homens brancos que negavam a Soujourner Truth o tal status de "mulher", mas também as mulheres brancas presentes, que gritavam: "Não deixem ela falar!" (hooks, 1990, p. 159). Logo, tal "lugar" é um não-lugar, a ponto de não poder haver alguém que fala, ou um lugar de quem não pode existir. hooks mostra que ao aparecerem raramente como um grupo distinto tanto dos homens negros quanto das mulheres brancas, as mulheres negras são um grupo cuja socialização da identidade ocorre "fora da existência" (hooks, 1990, p. 7). Algumas obras literárias mostram claramente esse ponto, como numa passagem de Everyone Was Brave de William O"Neills que faz referência à indignação de mulheres brancas ao verem que homens brancos apoiavam o voto dos "negros" mas não os das "mulheres". Nesse trecho, observa hooks, "a palavra homens de fato refere-se apenas a homens brancos, a palavra Negros (Negroes) refere-se apenas a homens negros, e a palavra mulheres refere-se a mulheres brancas" (ibid.). Aqui vemos a universalização operando na denominação do sujeito do feminismo centrado na figura da mulher branca, marginalizando a mulher negra por via do apagamento ${ }^{7}$. O sujeito autocentrado, geral, universal e neutro, reaparece, seja produzindo a marginalização que "localiza" um "outro" a partir de uma inferioridade, estranheza ou mesmo diferença, seja nem mesmo concebendo qualquer "outro", ou seja, agindo como se esse "outro" sequer existisse.

Evidenciando a posição autocentrada do sujeito branco, Maria Aparecida Silva Bento mostra, por exemplo, como o que é abordado geralmente como "problema do negro" é na verdade o problema do branco, dado que devido à sua posição autocentrada legitimada, o branco não tem de pensar sobre sua branquitude (2002, p. 15). A racialidade do branco, nas palavras de Bento, "é vivida

7 A invisibilidade na literatura é abordada por Barbara Smith em "Toward a Black Feminist Criticism" sobre mulheres negras escritoras e artistas e, em particular, lésbicas. 
como um círculo concêntrico: a branquitude se expande, se espalha, se ramifica e direciona o olhar do branco" (p. 16, grifo meu). A "linguagem da centralidade" como diz Spivak (1996, p. 34), recobre justamente a posição de poder do próprio movimento de centralização e marginalização, que produz o neutro e o diferente (e ainda o inexistente, como viemos de mencionar). Enquanto que a questão parece girar em torno de onde se encontra justamente o centro de gravidade que estabelece tais divisões opressoras.

Ao expor justamente estes centros de gravidade, seria então o caso de o movimento feminista em sua luta retomar o centro para-si, ocupá-lo? Ou esta pretensão deixaria intacto o movimento de centralização e exclusão? Butler critica Wittig, entre outras coisas, por seu objetivo de alcançar para as mulheres o status do sujeito universal (BUTLER, 1990, p. 20), pois isto faz com que esta última reforce os princípios da "metafísica da substância" que são as filosofias que se baseiam em uma ontologia substancial. A crítica ao traço "utópico" de Wittig nesta obra é extensa. Grosso modo, ela adverte sobre a ilusão da ideia de emancipação de um sujeito pré-social da liberdade humana - que se caracteriza em Wittig pela figura da lésbica - como reforço do modelo normativo do humanismo no centro do feminismo. No entanto, é interessante indagar a curiosa "centralização" visada por Wittig, na medida em que, como a própria Butler cita em seguida, "em busca dessa destruição, as "mulheres" [para Wittig] devem assumir um ponto de vista tanto particular quanto universal" (BUTLER, 1990, p.20, grifo meu). Se retormarmos o movimento de inverter e deslocar, não seria esta tentativa de reapropriação da centralidade enquanto "particular e universal" diferente da pretensão universalizante até aqui abordada? É fato que Wittig assume que "um texto escrito por um escritor minoritário só é eficaz se conseguir tornar universal o ponto de vista minoritário" (2018, p. 117). Porém, o que ocorre nesta "passagem" do "habitante das margens" pelo centro, levando consigo "ambos os ponto de vista particular e universal" de modo a colocar em questão a própria divisão e perturbar o poder centralizador?

Em Feminist theory: from margin to center, bell hooks (1984) fala da importância do transitar no centro quando se vive nas margens da cidade. Tal deslocamento acaba por descentralizar a própria "realidade" imposta pela divisão:

Vivendo como vivemos - no limite - desenvolvemos uma forma particular de ver a realidade. Olhamos tanto de fora para dentro como de dentro para fora. Concentramos a nossa atenção tanto no centro como na mar- 
gem. Entendemos ambos. Este modo de ver nos lembrou da existência de um universo inteiro, um corpo principal composto tanto de margem como de centro (hooks, 1984, s.p.)

Isto faz com que o sujeito marginal tenha uma visão do todo que o exclui, uma visão que abarca margem e centro, trazendo a desnaturalização da neutralidade e universalidade pretendida pela centralização. Neste sentido, talvez a pretensão ao universal de Wittig, na medida em que almeja manter ambos o particular e o universal, seja desmontada pelo lugar mesmo ocupado pelo sujeito minoritário. Por ser minoritário, e nesse sentido habitante das margens, o trânsito pelo centro perturba e dispersa a própria unidade da centralização:

Historicamente, o sujeito minoritário não é autocentrado como o sujeito logocêntrico. Sua extensão no espaço poderia ser descrita como o círculo de Pascal, cujo centro está em toda parte e cuja circunferência não está em lugar algum. O sujeito minoritário pode se dispersar em muitos centros, ele é necessariamente des-centrado, a-centrado. (WITTIG, 2018, p. 115)

Neste sentido, não estaria Wittig mais próxima do movimento de Spivak quando afirma que "Ao chamar a atenção para uma marginalidade feminista, tenho tentado, não ganhar o centro para nós, mas apontar para irredutibilidade da margem em todas as explicações" (1996, p.35)? Parece ser esta a força do movimento buscado pela escritora Elaine Brum (2019) ao clamar pela centralidade da floresta amazônica na era do colapso ecológico, no intuito de que ali onde o "fim do mundo" se anuncia, a centralização pode se tornar um meio para uma "nova forma de habitar a Terra": "deslocamos o que é centro e o que é periferia para recolocar o que estava deslocado". O corpo que se desloca para o novo centro e se encarna no corpo da floresta, no entanto, "é o ponto inicial de uma tessitura de múltiplas centralidades". Podemos pensar em novas formas de habitar proporcionadas pelos deslocamentos dos centros de gravidade de modo a subverter os movimentos de naturalização e legitimação de exclusão e de opressão. Ao inverter e deslocar, os lugares não são mais os mesmos, os solos giram, as centralidades se dispersam e a pretensão universal mostra sua caricatura sustentada pelos interesses econômicos-políticos e legitimada pelo pensamento. 
ANZALDÚA, G. La Prieta. In: . ; MORAGA, C. (Orgs) This bridge called my back. Writings by radical women of color. New York: Kitchen Table Women of color press, 1983.

BADIOU, A. L'Aventure de la philosophie française, Paris: La Fabrique, 2012.

BAMBARA, T. "Foreword". In: ANZALDÚA, G.; MORAGA, C. (Orgs) This bridge called my back. Writings by radical women of color. New York: Kitchen Table Women of color press, 1983.

BARBARAS, R. L'appartenance. Vers une cosmologie phénoménologique. Louvain-la-Neuve: 2019.

BEAUVOIR, S. Le Deuxième sexe. Tome I. Les faits et les mythes. Paris : Gallimard (Folio), 2014.

BENTO, M.A.S. Branqueamento e branquitude no Brasil In: . ; CARONE, I. (Orgs) Psicologia social do racismo - estudos sobre branquitude e branqueamento no Brasil. Petrópolis, RJ: Vozes, 2002, p. (25-58). Texto disponível em http://www.media. ceert.org.br/portal-3/pdf/publicacoes/branqueamento-e-branquitude-no-brasil.pdf

BRUM, E. Amazônia Centro do Mundo. El País 15/11/19. Disponível em: https://brasil.elpais.com/brasil/2019/11/15/opinion/1573820553 621324.html

BUTLER, J. Gender Trouble: feminism and subversion of identity. New York: Routledge, 1990.

CYFER, I. "Afinal, o que é uma mulher? Simone de Beauvoir e 'a questão do sujeito' na teoria crítica feminista. Lua Nova, São Paulo, 94: 41-77, 2015.

CRENSHAW, K.W. "Cartographies des marges : intersectionnalité, politique de l'identité et violences contre les femmes de couleur". Paris: L'Harmattan. Cahiers $d u$ Genre, $\mathrm{n}^{\circ} 39,2005$, pp. 51-82.
DORLIN, E. Sexe, genre et sexualité. Paris : PUF, 2019.

HOOKS, B. Feminist theory from margin to center. Boston: South End Press, 1984.

Ain't I a woman? London: Pluto Press, 1990.

PRECIADO, P.B. Un appartement sur Uranus. Chroniques de la traversée. Paris: Grasset, 2019.

RODRIGUES, C. ; LOBATO, A.E. "Os feminismos e seus sujeitos" Princípios: Revista de Filosofia, Natal, v. 27, n. 52, jan.-abr. 2020, Natal.

SMITH, B. Toward a Black Feminist Criticism. The Radical Teacher, No. 7 (March, 1978), pp. 20-27.

SPIVAK, G. "Explanation and Culture: marginalia". In: LANDRY, D. ; MACLEAN, G. (Orgs) The Spivak reader. Selected works of Gayatri Chakravorty Spivak. New York: Routledge, 1996.

WITTIG, M. Les Guérillères. Paris: Minuit, 2019.

“La pensée straight". In:

BOURCIER, S. (Org) La pensée straight. Paris: Éd. Amsterdam, 2018.

.Le point de vue: universal ou particulier" In: ; BOURCIER, S. (Org) La pensée straight. Paris: Éd. Amsterdam, 2018.

.'On ne naît pas femme" In:

BOURCIER, S. (Org) La pensée straight. Paris: Éd. Amsterdam, 2018.

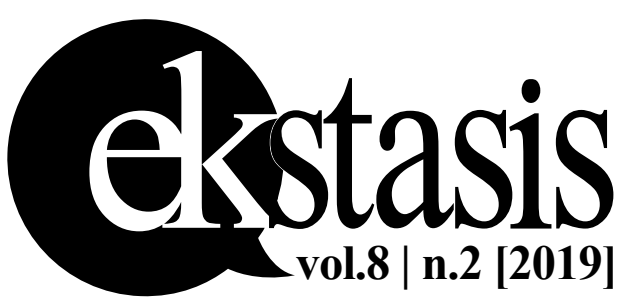

